\title{
Vitamin D deficiency is associated with increased risk of bacterial infections after kidney transplan- tation
}

Young-Jae Park ${ }^{1}$ Sang-Un Kim ${ }^{1}$, Kyung-Hee Lee ${ }^{1}$, Jong-Hak Lee ${ }^{1}$, Eugene Kwon ${ }^{1}$, Hee-Yeon Jung ${ }^{1}$, Ji-Young Choi ${ }^{1}$, Jang-Hee Cho ${ }^{1}$, Sun-Hee Park ${ }^{1}$, Yong-Lim Kim ${ }^{1}$, Hyung-Kee Kim² ${ }^{2}$, Seung Huh ${ }^{2}$, and Chan-Duck Kim ${ }^{1}$

Departments of ${ }^{1}$ Internal Medicine and ${ }^{2}$ Surgery, Kyungpook National University School of Medicine, Daegu, Korea

Received: July 11, 2015

Revised : August 22, 2015

Accepted: September 9, 2015

\section{Correspondence to}

Chan-Duck Kim, M.D.

Division of Nephrology,

Department of Internal Medicine,

Kyungpook National University

School of Medicine, 130

Dongdeok-ro, Jung-gu, Daegu

41944, Korea

Tel: +82-53-200-5560

Fax: +82-53-423-7583

E-mail: drcdkim@knu.ac.kr
Background/Aims: There may be an association between vitamin D levels and allograft outcomes in kidney transplant recipients (KTRs). However, few studies have been conducted to determine the association between vitamin D levels and post-transplant infections. This study investigated the impact of vitamin D deficiency on the risk of infection after kidney transplantation.

Methods: We measured 25-hydroxyvitamin D (25(OH)D) levels prior to kidney transplantation. Vitamin D deficiency was defined as a serum $25(\mathrm{OH}) \mathrm{D}$ level $<20$ $\mathrm{ng} / \mathrm{mL}$. We examined the incidence of various post-transplant infections during follow-up period. We used Cox proportional hazards regression analysis to determine factors associated with increased risk of post-transplant infections during the follow-up period.

Results: A total of 164 KTRs were followed up for a mean of $24.8 \pm 10.7$ months. Among them, 135 patients (82.3\%) had vitamin D deficiency. Patients with vitamin $\mathrm{D}$ deficiency had a significantly higher incidence of urinary tract infection ( $p=$ 0.027 ) and any bacterial infection $(p=0.010)$ compared to those without vitamin D deficiency. Vitamin D deficiency was not significantly associated with incidence of viral or fungal infections. Cox proportional hazards regression analysis revealed that vitamin D deficiency (hazard ratio, 11.07; 95\% confidence interval, 1.46 to $84.03 ; p=0.020$ ) was independent risk factor for post-transplant bacterial infections.

Conclusions: Pre-transplant vitamin D deficiency was a significant risk factor for bacterial infections after kidney transplantation. Further studies are needed on possible benefits of vitamin D supplementation for preventing post-transplant bacterial infection.

Keywords: Vitamin D deficiency; Kidney transplantation; Bacterial infections

\section{INTRODUCTION}

Vitamin D is synthesized in humans following exposure to ultraviolet $\mathrm{B}$ radiation, or is obtained through food or supplementation. Vitamin D deficiency can therefore be caused by inadequate intake from diet or supplements or insufficient sun exposure. Vitamin D has a variety of roles within the human body, including regulation of 
calcium and phosphorus homeostasis. Vitamin D deficiency causes skeletal diseases such as rickets, and has been associated with cardiovascular and autoimmune diseases, malignancy, and mood disorders in the general public [1-3].

Vitamin D regulates diverse aspects of the immune system. Vitamin D receptors are located on many immune cells, including monocytes, macrophages, $\mathrm{T}$ and B lymphocytes, and dendritic cells. Several experimental studies have shown that vitamin D can enhance innate immune clearance of pathogens and promote proliferation and secretion of highly inflammatory interleukin-1 $[4,5]$. Vitamin D deficiency has been associated with increased incidence of infectious disease, especially respiratory tract diseases, and infection-associated mortality in the general population $[6,7]$. However, this has not been investigated specifically in kidney transplant recipients (KTRs).

Vitamin D deficiency is more common in patients with chronic kidney disease (CKD) and KTRs than the general population, and associated with increased mortality of CKD patients [8-11]. Studies reported that vitamin D deficiency in KTRs affects graft function and decreases the glomerular filtration rate (GFR) $[12,13]$. Similar to the general population, vitamin D deficiency was linked to increased malignancy in KTRs [14].

Few studies have been conducted to define any association between vitamin $\mathrm{D}$ levels and post-transplant infections in KT'Rs. Moreover, although evidence is lacking that bacterial infections increase the chances for graft loss and decrease GFR after kidney transplantation, bacterial infections can increase mortality risk $[15,16]$. Therefore, investigation of risk factors that might increase the risk of bacterial infections in KTRs could be important issue. This study investigated the impact of vitamin $\mathrm{D}$ deficiency on the development of infections after kidney transplantation.

\section{METHODS}

\section{Study population}

We retrospectively investigated the medical records of 174 patients who had undergone kidney transplantation at Kyungpook National University Hospital between January 2011 and December 2013. Among these KTRs, we enrolled 164 whose 25 -hydroxyvitamin D $(25(\mathrm{OH}) \mathrm{D})$ levels were measured within 2 weeks prior to kidney transplantation. Most KTRs were received basiliximab (20 mg), as induction therapy, on day o and day 4 and were prescribed tacrolimus, mycophenolate mofetil, and prednisone as maintenance immunosuppression. The study was approved by the Institutional Review Board of the Kyungpook National University Hospital and was in accordance with the Helsinki Declaration. We did not obtain written consents from participants in this retrospective study because patient information was anonymized and de-identified prior to analysis. The Institutional Review Board of the Kyungpook National University Hospital ensured the anonymity of the data and approved this consent procedure.

\section{Data collection and biochemistry}

Demographic and clinical data analyzed in this study included age, sex, body mass index (BMI), renal replacement therapy before kidney transplantation, etiologies of end-stage renal disease (ESRD), transplant type, donor age, cold ischemic time, and human leukocyte antigen (HLA) mismatch number. Laboratory data included hemoglobin levels, white blood cell count, blood urea nitrogen, creatinine, sodium, potassium, and blood glucose levels. The serum $25(\mathrm{OH}) \mathrm{D}$ concentrations were measured using a radioimmunoassay (DiaSorin, Stillwater, MN, USA). Although no consensus has been reached on optimal serum $25(\mathrm{OH}) \mathrm{D}$ concentration, vitamin $\mathrm{D}$ deficiency is defined as a $25(\mathrm{OH}) \mathrm{D}$ concentration $<20$ $\mathrm{ng} / \mathrm{mL}$ (50 nmol/L) [17,18]. This concentration was therefore used to define vitamin D deficiency in this study.

\section{Follow-up and end points}

All KTRs were regularly examined at Kyungpook National University Hospital. All infections, hospitalizations events, graft function, and mortalities were recorded. The primary end point was development of any infection after kidney transplantation. The secondary end points were allograft failure or patient death after kidney transplantation.

\section{Statistical analysis}

The results were expressed as mean \pm SD or numbers (percentage). The KTRs were divided into two groups based on their pre-transplant serum $25(\mathrm{OH}) \mathrm{D}$ con- 
centrations $(<20$ and $\geq 20 \mathrm{ng} / \mathrm{mL})$. The baseline characteristics of each group were compared using the Mann-Whitney $U$ test for continuous variables and the chi-square test for categorical variables. Independent factors that associated with any bacterial infection were extracted using multivariate Cox proportional hazards regression analysis, which was adjusted for presence or absence of vitamin D deficiency, patient's age, sex, pre-transplant BMI, ESRD etiologies, modality of renal replacement therapy prior to kidney transplantation, donor type, cold ischemic time, desensitization prior to kidney transplantation, and hemoglobin levels. Cumulative survival curves using the Kaplan-Meier method were utilized to obtain graph association between vitamin D deficiency and bacterial infections. A $p<0.05$ was considered statistically significant. All analyses were performed using statistical software SPSS version 19.0 (IBM Co., Armonk, NY, USA).

\section{RESULTS}

\section{Baseline characteristics of patients}

A total of 164 KTRs were followed up for a mean of $24.8 \pm 10.7$ months. The mean concentration of serum $25(\mathrm{OH}) \mathrm{D}$ was $13.87 \pm 8.39 \mathrm{ng} / \mathrm{mL}$, and $135 \mathrm{KTRs}(82.3 \%)$ had vitamin D deficiency. The demographics and clinical and biochemical data of enrolled patients divided by their pre-transplant serum $25(\mathrm{OH}) \mathrm{D}$ concentrations are presented in Table 1. The mean concentrations of serum $25(\mathrm{OH}) \mathrm{D}$ in patients with and without vitamin $\mathrm{D}$ deficiency were $10.97 \pm 4.69$ and $27.34 \pm 8.70 \mathrm{ng} / \mathrm{mL}$, respectively. The mean ages of patients with and without vitamin D deficiency were $46.22 \pm 12.26$ and $48.21 \pm 13.89$ years, respectively. There were no significant differences between the two groups in age, sex, pre-transplant BMI, donor age, HLA mismatch number, modality of renal replacement therapy prior to kidney transplantation, laboratory results except serum 25(OH)D and hemoglobin level, and desensitization treatment before kidney transplantation. However, the etiologies of ESRD significantly differed between the two groups $(p=0.043)$. The most common cause of ESRD was glomerulonephritis (59.8\% and $58.6 \%$, respectively) and the proportion of diabetic nephropathy was significantly higher among patients with vitamin D deficiency. The donor type significantly

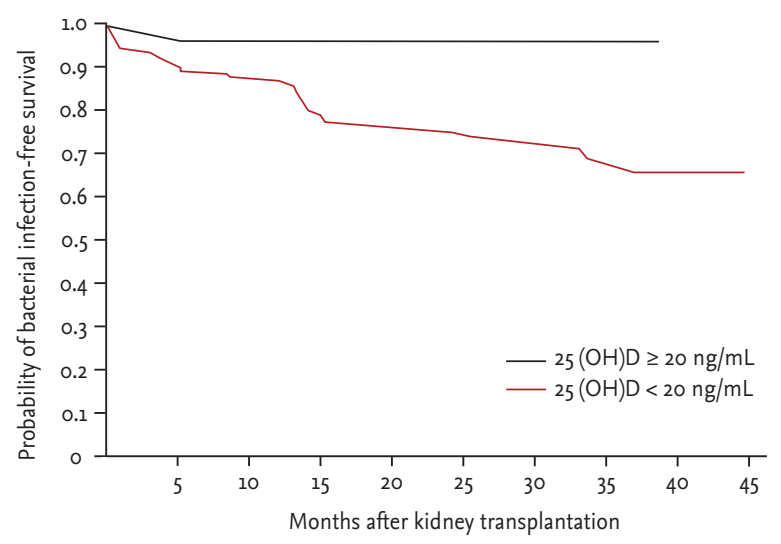

Figure 1. Bacterial infection-free survival was significantly lower in patients with vitamin $\mathrm{D}$ deficiency than in patients without vitamin D deficiency as shown by the Kaplan-Meier curves $(p=0.021)$. 25(OH)D, 25-hydroxyvitamin D.

differed between the two groups $(p=0.006)$. The proportion of living donors was significantly higher among patients with vitamin D deficiency. Cold ischemic time was significantly shorter among patients with vitamin $\mathrm{D}$ deficiency.

\section{Frequencies and types of infections after kidney transplantation}

Among 164 KTRs, 35 (21.3\%) experienced bacterial infections. Urinary tract infection, which was defined as a urine culture containing more than 100,000 colony-forming units per $\mathrm{mL}$ with typical symptoms or signs, was the most common bacterial infection (19 KTRs, $11.5 \%$ ), and bacterial pneumonia was the second most common (seven KTRs, 4.3\%); other bacterial infections that occurred at lower rates included peritonitis, infective endocarditis, infectious colitis, otitis media, arteriovenous graft infection, cellulitis, sinusitis, perianal abscess, and wound infection. The frequency of urinary tract infections was significantly higher in patients with vitamin D deficiency (19/135, 14.1\%) than in patients without vitamin D deficiency $(0 / 29,0 \%)(p=0.027)$. In KTRs with vitamin D deficiency, 34 (25.2\%) experienced bacterial infections compared with only one patient (3.4\%) without vitamin $\mathrm{D}$ deficiency. The frequency of bacterial infections significantly differed between the two groups $(p=0.010)$ (Table 2). Bacterial infection-free survival was significantly lower in patients with vitamin $\mathrm{D}$ deficiency than in patients without vitamin D deficiency, as depicted using Kaplan-Meier curves $(p=0.021)$ (Fig. 1$)$. The 
Table 1. Characteristics of patients grouped by serum vitamin $\mathrm{D}$ concentration

\begin{tabular}{|c|c|c|c|}
\hline Characteristic & $25(\mathrm{OH}) \mathrm{D}<20 \mathrm{ng} / \mathrm{mL}(\mathrm{n}=135)$ & $25(\mathrm{OH}) \mathrm{D} \geq 20 \mathrm{ng} / \mathrm{mL}(\mathrm{n}=29)$ & $p$ value \\
\hline \multicolumn{4}{|l|}{ Demographic } \\
\hline Age at transplantation, yr & $46.22 \pm 12.26$ & $48.21 \pm 13.89$ & 0.236 \\
\hline Male sex (recipient) & $94(69.6)$ & $22(75.9)$ & 0.503 \\
\hline Pre-transplant BMI, kg/m² & $21.90 \pm 3.20$ & $21.35 \pm 3.38$ & 0.511 \\
\hline Etiologies of ESRD & & & 0.043 \\
\hline Diabetic nephropathy & $41(30.4)$ & $5(17.2)$ & \\
\hline Hypertension & $5(3 \cdot 7)$ & $5(17.2)$ & \\
\hline Glomerulonephritis & $80(59 \cdot 3)$ & $17(58.6)$ & \\
\hline Other & $9(6.7)$ & $2(6.9)$ & \\
\hline Renal replacement therapy before KT & & & 0.136 \\
\hline $\mathrm{HD}$ & $76(56.3)$ & $23(79 \cdot 3)$ & \\
\hline $\mathrm{PD}$ & $20(14.8)$ & $3(10.3)$ & \\
\hline $\mathrm{HD}+\mathrm{PD}$ & $3(2.2)$ & 0 & \\
\hline Preemptive KT & $36(26.7)$ & $3(10.3)$ & \\
\hline Transplant type & & & 0.006 \\
\hline Living donor & $80(59 \cdot 3)$ & $9(31.0)$ & \\
\hline Deceased donor & $55(40.7)$ & $20(69.0)$ & \\
\hline \multicolumn{4}{|l|}{ Donor characteristics } \\
\hline Donor age, yr & $44.83 \pm 14.47$ & $44.63 \pm 16.19$ & 0.523 \\
\hline Cold ischemic time, min & $159.26 \pm 141.98$ & $211.21 \pm 128.27$ & 0.014 \\
\hline Total HLA mismatch & $3.10 \pm 1.64$ & $3.24 \pm 1.62$ & 0.576 \\
\hline HLA-DR mismatch & $1.07 \pm 0.67$ & $1.00 \pm 0.76$ & 0.652 \\
\hline \multicolumn{4}{|l|}{ Laboratory results (pre-transplant) } \\
\hline $25(\mathrm{OH}) \mathrm{D}, \mathrm{ng} / \mathrm{mL}$ & $10.97 \pm 4.69$ & $27 \cdot 34 \pm 8.70$ & $<0.001$ \\
\hline Hemoglobin, g/dL & $10.35 \pm 1.68$ & $11.64 \pm 1.36$ & $<0.001$ \\
\hline $\mathrm{WBC}, / \mu \mathrm{L}$ & $6,966.51 \pm 2,673 \cdot 72$ & $6,939.29 \pm 2,451.27$ & 0.843 \\
\hline $\mathrm{BUN}, \mathrm{mg} / \mathrm{dL}$ & $57.39 \pm 32.68$ & $47.55 \pm 19.80$ & 0.288 \\
\hline Creatinine, mg/dL & $8.97 \pm 4.32$ & $9.15 \pm 3.14$ & 0.505 \\
\hline Sodium, mmol/L & $137.26 \pm 4.13$ & $138.20 \pm 4.13$ & 0.212 \\
\hline Potassium, mmol/L & $4.70 \pm 0.78$ & $4.81 \pm 0.68$ & 0.529 \\
\hline Blood sugar, mg/dL & $130.84 \pm 84.93$ & $108.54 \pm 28.92$ & 0.334 \\
\hline Desensitization & $22(16.3)$ & $6(20.7)$ & 0.589 \\
\hline
\end{tabular}

Values are presented as mean $\pm \mathrm{SD}$ or number $(\%)$.

${ }_{25}(\mathrm{OH}) \mathrm{D}, 25$-hydroxyvitamin D; BMI, body mass index; ESRD, end-stage renal disease; KT, kidney transplantation; HD, hemodialysis; PD, peritoneal dialysis; HLA, human leukocyte antigen; WBC, white blood cell; BUN, blood urea nitrogen.

occurrence of viral infections, such as cytomegalovirus and BK virus, did not significantly differ between the two groups (Table 2).

\section{Risk factors for the development of bacterial infec- tions after kidney transplantation}

We analyzed the risk factors for any bacterial infection after kidney transplantation. In univariate Cox regression analysis, serum $25(\mathrm{OH}) \mathrm{D}$ concentration less than 20 $\mathrm{ng} / \mathrm{mL}$ (hazard ratio [HR], 7.38; 95\% confidence interval [CI], 1.01 to 53.92; $p=0.049)$, female sex $(\mathrm{HR}, 2.58 ; 95 \%$ CI, 1.33 to $5.01 ; p=0.005)$, and desensitization treatment prior to kidney transplantation (HR, 2.99; 95\% CI, 1.39 to $5.99 ; p=0.004$ ) associated with the development of 
Table 2. Frequencies and types of infections after kidney transplantation

\begin{tabular}{|c|c|c|c|}
\hline Variable & $25(\mathrm{OH}) \mathrm{D}<20 \mathrm{ng} / \mathrm{mL}(\mathrm{n}=135)$ & ${ }_{25}(\mathrm{OH}) \mathrm{D} \geq 20 \mathrm{ng} / \mathrm{mL}(\mathrm{n}=29)$ & $p$ value \\
\hline Urinary tract infection & $19(14.1)$ & 0 & 0.027 \\
\hline Bacterial pneumonia & $6(4 \cdot 4)$ & $1(3.4)$ & 1.000 \\
\hline CMV infections & $16(11.9)$ & $2(6.9)$ & 0.743 \\
\hline $\mathrm{BK}$ virus infections & $16(11.9)$ & $3(10.3)$ & 1.000 \\
\hline Any bacterial infection ${ }^{a}$ & $34(25.2)$ & $1(3.4)$ & 0.010 \\
\hline
\end{tabular}

Values are presented as number (\%).

25(OH)D, 25-hydroxyvitamin D; CMV, cytomegalovirus.

${ }^{a}$ Any bacterial infections include peritonitis, infective endocarditis, infectious colitis, otitis media, arteriovenous graft infection, cellulitis, sinusitis, perianal abscess, and wound infection.

Table 3. Risk factors for the development of any bacterial infections after kidney transplantation

\begin{tabular}{|c|c|c|c|c|}
\hline \multirow{2}{*}{ Variable } & \multicolumn{2}{|c|}{ Unadjusted } & \multicolumn{2}{|c|}{ Fully adjusted } \\
\hline & $\mathrm{HR}(95 \% \mathrm{CI})$ & $p$ value & $\mathrm{HR}(95 \% \mathrm{CI})$ & $p$ value \\
\hline $25(\mathrm{OH}) \mathrm{D}<20 \mathrm{ng} / \mathrm{mL}$ & $7.38(1.01-53.92)$ & 0.049 & $11.07(1.46-84.03)$ & 0.020 \\
\hline Age at transplant & $1.02(0.99-1.05)$ & 0.196 & $1.04(0.997-1.08)$ & 0.072 \\
\hline Female sex & $2.58(1.33-5.01)$ & 0.005 & $1.94(0.85-4.43)$ & 0.115 \\
\hline Pre-transplant BMI & $0.91(0.82-1.02)$ & 0.114 & $0.92(0.79-1.07)$ & 0.261 \\
\hline \multicolumn{5}{|l|}{ Etiology of ESRD } \\
\hline Diabetic nephropathy & $1.15\left(0.55^{-2.38)}\right.$ & 0.716 & $1.04\left(0.45^{-2.40}\right)$ & 0.923 \\
\hline Hypertension & $0.85(0.20-3.66)$ & 0.832 & $1.35(0.28-6.50)$ & 0.709 \\
\hline Renal replacement therapy before KT & $1.45(0.60-3.50)$ & 0.407 & $0.92(0.30-2.77)$ & 0.878 \\
\hline Deceased donor & $1.88(0.96-3.70)$ & 0.068 & $2.98(1.01-8.84)$ & 0.049 \\
\hline Cold ischemic time & $1.00(1.00-1.01)$ & 0.206 & $1.00(0.996-1.002)$ & 0.381 \\
\hline Desensitization & $2.98(1.39-5.99)$ & 0.004 & $3.17(1.30-7.70)$ & 0.011 \\
\hline Baseline hemoglobin & $1.12(0.92-1.36)$ & 0.269 & $1.04(0.83-1.31)$ & 0.722 \\
\hline
\end{tabular}

HR, hazard ratio; CI, confidence interval; $25(\mathrm{OH}) \mathrm{D}$, 25-hydroxyvitamin D; BMI, body mass index; ESRD, end-stage renal disease; KT, kidney transplantation.

any bacterial infections after kidney transplantation. Patients' age, pre-transplant BMI, ESRD etiologies, modality of renal replacement therapy prior to kidney transplantation, donor type, cold ischemic time, and baseline hemoglobin were not associated with the development of bacterial infections. Multivariate Cox regression analysis, which included the variables that were significant in the univariate Cox regression analysis and the variables (pre-transplant BMI and donor type) that were significant in the previous studies [19], revealed that serum $25(\mathrm{OH}) \mathrm{D}$ concentration less than $20 \mathrm{ng} / \mathrm{mL}$ (HR, 9.12; 95\% CI, 1.24 to $66.92 ; p=0.030$ ) was independent risk factor for the development of bacterial infections after kidney transplantation. When all variables included in the multivariate Cox regression analysis, serum $25(\mathrm{OH})$ D concentration less than $20 \mathrm{ng} / \mathrm{mL}$ (HR, 11.07; 95\% CI, 1.46 to $84.03 ; p=0.020$ ), desensitization treatment prior to kidney transplantation (HR, 3.17; 95\% CI, 1.30 to 7.70 ; $p=0.011)$ and deceased donor (HR, 2.98; 95\% CI, 1.01 to $8.84 ; p=0.049$ ) were independent risk factors for the development of bacterial infections after kidney transplantation (Table 3).

\section{Frequencies of rejection, allograft failure and patient death}

Among 164 KT'Rs, eight patients (4.9\%) were diagnosed biopsy-proven acute rejection and one restart dialysis (0.6\%) due to allograft failure, and five (3.0\%) died during 
Table 4. Frequencies of biopsy proven acute rejection, allograft failure, patient death, and allograft function after kidney transplantation

\begin{tabular}{lccc}
\hline Variable & $25(\mathrm{OH}) \mathrm{D}<20 \mathrm{ng} / \mathrm{mL}(\mathrm{n}=135)$ & $25(\mathrm{OH}) \mathrm{D} \geq 20 \mathrm{ng} / \mathrm{mL}(\mathrm{n}=29)$ & $p$ value \\
\hline Biopsy proven acute rejection & $8(5.9)$ & $1(3.4)$ & 0 \\
Allograft failure & $1(0.7)$ & 1.000 & 1.000 \\
Patient death & $4(3.0)$ & $1.35 \pm 0.54$ & 1.000 \\
Last creatinine, $\mathrm{mg} / \mathrm{dL}$ & $1.35 \pm 0.89$ & $60.18 \pm 19.15$ & 0.977 \\
$\begin{array}{l}\text { Last eGFR, } \mathrm{mL} / \mathrm{min} / 1.73 \mathrm{~m}^{2} \\
\text { (calculated by MDRD equation) }\end{array}$ & $62.64 \pm 19.79$ & & 0.538 \\
\hline
\end{tabular}

Values are presented as number (\%).

25(OH)D, 25-hydroxyvitamin D; eGFR, estimated glomerular filtration rate; MDRD, Modification of Diet in Renal Disease.

follow-up period. The frequencies of biopsy-proven acute rejection, allograft failure and patient death did not significantly differ between the two groups. Serum creatinine concentration and estimated GFR calculated by the Modification of Diet in Renal Disease equation that had been measured at last follow-up did not differ between the two groups (Table 4).

\section{DISCUSSION}

This study determined the association between vitamin D deficiency and risk of bacterial infection after kidney transplantation. Vitamin D deficiency was common (82.3\%) in KTRs who enrolled in our study, and the frequency of any bacterial infections was significantly higher in patients with vitamin D deficiency. Moreover, vitamin D deficiency was an independent risk factor for the development of any bacterial infection after kidney transplantation.

In previous studies, the prevalence of vitamin $\mathrm{D}$ deficiency among KT'Rs was reported as $38.7 \%$ to $61.5 \%$ $[12,14,20-22]$. However, because the definition of vitamin $\mathrm{D}$ deficiency varied among studies, the precise prevalence of vitamin D deficiency in KTRs is unclear. The United States Institute of Medicine defined vitamin D deficiency as serum $25(\mathrm{OH}) \mathrm{D}$ concentration $<20 \mathrm{ng} / \mathrm{mL}$, the same value utilized in the Endocrine Society Clinical Practice 2011 Guideline [23]. This value has also been utilized to define vitamin D deficiency in recent studies $[17,18]$, so we also adopted this definition for our study. Utilizing this definition, $82.3 \%$ of the KTRs in our study had vitamin D deficiency, which was significantly higher than the incidence reported in previous studies. KTRs may have vitamin $\mathrm{D}$ deficiency due to decreased sunlight exposure resulting from reduced outdoor activity, increased vitamin D catabolism due to immunosuppressive treatment, and enhanced degradation of $25(\mathrm{OH})$ D caused by fibroblast growth factor 23 [24-26]. Previous studies reported that female sex, diabetes and peritoneal dialysis were associated with low serum vitamin $\mathrm{D}$ concentrations in patients with CKD $[27,28]$. In our study, significantly more patients were diabetic nephropathy and more patients were female and on peritoneal dialysis as pre-transplantation treatment modality, although there were no statistically significant differences, in patients with vitamin $\mathrm{D}$ deficiency. Therefore, there may be a possibility that the high frequency of urinary tract infection in KTRs with vitamin D deficiency in our study is associated with the high proportion of diabetic nephropathy and female sex [29], which are known risk factors of urinary tract infection, in KTRs with vitamin D deficiency. Nevertheless, multivariate Cox regression analysis revealed that vitamin D deficiency was independent risk factor for the posttransplant any bacterial infections including urinary tract infection after adjusting for variables including sex and the etiologies of ESRD.

Vitamin D plays various roles in multiple organ systems and important roles in regulating the immune system. Immune cells such as macrophages and monocytes contain antimicrobial proteins, including cathelicidin and $\beta$-defensin. Vitamin D promotes maturation of immune cells and production of these antimicrobial proteins [30,31]. Hence, vitamin D deficiency may increase bacterial infections. However, there is little data describing the relationship between vitamin D deficiency and the development of bacterial infections in KTRs. Similar to our study, Kwon et al. [19] recently reported that 
post-transplant urinary tract infections were more common in KTRs with pre-transplant vitamin D deficiency than in those without, and vitamin D deficiency was an independent risk factor for increased urinary tract infections after kidney transplantation. However, their study measured only serum $25(\mathrm{OH}) \mathrm{D}_{3}$ concentrations, while we measured total serum $25(\mathrm{OH}) \mathrm{D}[25(\mathrm{OH}) \mathrm{D} 2+$ $\left.25(\mathrm{OH}) \mathrm{D}_{3}\right]$. Total $25(\mathrm{OH}) \mathrm{D}$ level has been established as a reliable biomarker for vitamin D status [17]. Moreover, we investigated any bacterial infection including urinary tract infection and viral infections, and showed that vitamin $\mathrm{D}$ deficiency was an independent risk factor for the development of any bacterial infection after kidney transplantation.

Previous several studies revealed that vitamin D deficiency increases the incidence of graft dysfunction, allograft failure and patient death in KTRs [12,13,32,33]. However, in our study, there were no significant differences in the frequencies of biopsy-proven acute rejection, allograft failure, and patient death between the two groups because of a small number of cases with relatively short-term follow-up duration after kidney transplantation. Further large scale studies with longterm follow-up duration will be needed to ascertain the impact of vitamin D deficiency on graft and patient survival.

There are several retrospective studies about vitamin D supplementation and graft outcome of KTRs. Researchers demonstrated that treatment with vitamin D decreases acute cellular rejection episodes and improves graft survival [34-37]. However, there are very few randomized controlled trials about treatment of KTRs with vitamin D supplements. Until now, there has been no study about vitamin D treatment and the development of infections in KTRs.

This study has several limitations. First, a small proportion of KTRs had serial serum $25(\mathrm{OH}) \mathrm{D}$ concentrations, so it was difficult to evaluate whether the change in vitamin D concentration had an effect on the development of bacterial infections after kidney transplantation. Second, comorbidities associated with bacterial infections were not evaluated in this study, such as chronic lung disease, inactivity, poor nutritional status, and urogenital abnormalities after kidney transplantation.

In conclusion, vitamin D deficiency was common in patients with ESRD prior to kidney transplantation and was a significant risk factor for post-transplant bacterial infections. Further studies will be needed to ascertain whether vitamin D supplementation will help prevent post-transplant bacterial infections in vitamin $\mathrm{D}$ deficient KTRs.

\section{KEY MESSAGE}

1. Patients with vitamin D deficiency had a significantly higher incidence of urinary tract infection and any bacterial infection compared to those without vitamin D deficiency.

2. Pre-transplant vitamin D deficiency was a significant risk factor for bacterial infections after kidney transplantation.

\section{Conflict of interest}

No potential conflict of interest relevant to this article was reported.

\section{Acknowledgments}

This study was supported by a grant from the Korean Health Technology R\&D Project, Ministry of Health and Welfare, Republic of Korea ( $\left.\mathrm{HI}_{13} \mathrm{Cl}_{12} 2\right)$.

\section{REFERENCES}

1. Pludowski P, Holick MF, Pilz S, et al. Vitamin D effects on musculoskeletal health, immunity, autoimmunity, cardiovascular disease, cancer, fertility, pregnancy, dementia and mortality: a review of recent evidence. Autoimmun Rev 2013;12:976-989.

2. Wang TJ, Pencina MJ, Booth SL, et al. Vitamin D deficiency and risk of cardiovascular disease. Circulation 2008;117:503-511.

3. Holick MF. Vitamin D: its role in cancer prevention and treatment. Prog Biophys Mol Biol 2006;92:49-59.

4. Bhalla AK, Amento EP, Krane SM. Differential effects of 1,25-dihydroxyvitamin $\mathrm{D}_{3}$ on human lymphocytes and monocyte/macrophages: inhibition of interleukin-2 and augmentation of interleukin-1 production. Cell Immunol 1986;98:311-322.

5. Wang TT, Nestel FP, Bourdeau V, et al. Cutting edge: 
1,25-dihydroxyvitamin $\mathrm{D}_{3}$ is a direct inducer of antimicrobial peptide gene expression. J Immunol 2004;173:29092912.

6. Hong JY, Kim SY, Chung KS, et al. Association between vitamin $\mathrm{D}$ deficiency and tuberculosis in a Korean population. Int J Tuberc Lung Dis 2014;18:73-78.

7. de Haan K, Groeneveld AB, de Geus HR, Egal M, Struijs A. Vitamin $\mathrm{D}$ deficiency as a risk factor for infection, sepsis and mortality in the critically ill: systematic review and meta-analysis. Crit Care 2014;18:66o.

8. Mehrotra R, Kermah D, Budoff M, et al. Hypovitaminosis D in chronic kidney disease. Clin J Am Soc Nephrol 2008;3:1144-1151.

9. Navaneethan SD, Schold JD, Arrigain S, et al. Low 25-hydroxyvitamin D levels and mortality in non-dialysis-dependent CKD. Am J Kidney Dis 2011;58:536-543.

10. Kim CS, Kim SW. Vitamin D and chronic kidney disease. Korean J Intern Med 2014;29:416-427.

11. Stavroulopoulos A, Cassidy MJ, Porter CJ, Hosking DJ, Roe SD. Vitamin D status in renal transplant recipients. Am J Transplant 2007;7:2546-2552.

12. Kim H, Kang SW, Yoo TH, et al. The impact of pretransplant 25-hydroxy vitamin D deficiency on subsequent graft function: an observational study. BMC Nephrol 2012;13:22.

13. Falkiewicz K, Boratynska M, Speichert-Bidzinska B, et al. 1,25-dihydroxyvitamin $\mathrm{D}$ deficiency predicts poorer outcome after renal transplantation. Transplant Proc 2009;41:3002-3005.

14. Ducloux D, Courivaud C, Bamoulid J, Kazory A, Dumoulin G, Chalopin JM. Pretransplant serum vitamin D levels and risk of cancer after renal transplantation. Transplantation 2008;85:1755-1759.

15. Chuang P, Parikh CR, Langone A. Urinary tract infections after renal transplantation: a retrospective review at two US transplant centers. Clin Transplant 2005;19:230-235.

16. Ariza-Heredia EJ, Beam EN, Lesnick TG, Cosio FG, Kremers WK, Razonable RR. Impact of urinary tract infection on allograft function after kidney transplantation. Clin Transplant 2014;28:683-690.

17. Holick MF. Vitamin D deficiency. N Engl J Med 2007;357:266281.

18. McGregor R, Li G, Penny H, Lombardi G, Afzali B, Goldsmith DJ. Vitamin D in renal transplantation: from biological mechanisms to clinical benefits. Am J Transplant 2014;14:1259-1270.
19. Kwon YE, Kim H, Oh HJ, et al. Vitamin D deficiency is an independent risk factor for urinary tract infections after renal transplants. Medicine (Baltimore) 2015;94:e594.

20. Lee JR, Dadhania D, August P, Lee JB, Suthanthiran M, Muthukumar T. Circulating levels of 25-hydroxyvitamin $\mathrm{D}$ and acute cellular rejection in kidney allograft recipients. Transplantation 2014;98:292-299.

21. Marcen R, Jimenez S, Fernandez-Rodriguez A, et al. Are low levels of 25-hydroxyvitamin D a risk factor for cardiovascular diseases or malignancies in renal transplantation? Nephrol Dial Transplant 2012;27 Suppl 4:iv47-iv52.

22. Kanter Berga J, Crespo Albiach J, Beltran Catalan S, et al. Vitamin D deficiency in a renal transplant population: safe repletion with moderate doses of calcidiol. Transplant Proc 2010;42:2917-2920.

23. Ross AC, Manson JE, Abrams SA, et al. The 2011 report on dietary reference intakes for calcium and vitamin $\mathrm{D}$ from the Institute of Medicine: what clinicians need to know. J Clin Endocrinol Metab 2011;96:53-58.

24. Eyal O, Aharon M, Safadi R, Elhalel MD. Serum vitamin D levels in kidney transplant recipients: the importance of an immunosuppression regimen and sun exposure. Isr Med Assoc J 2013;15:628-633.

25. Shimada T, Hasegawa H, Yamazaki Y, et al. FGF-23 is a potent regulator of vitamin $\mathrm{D}$ metabolism and phosphate homeostasis. J Bone Miner Res 2004;19:429-435.

26. Kuro-o M. Klotho and the aging process. Korean J Intern Med 2011;26:113-122.

27. Clayton P, Singer R. 25-Hydroxyvitamin D levels in prevalent Australian dialysis patients. Nephrology (Carlton) 2009;14:554-559.

28. Elder GJ. Vitamin D levels, bone turnover and bone mineral density show seasonal variation in patients with chronic kidney disease stage 5. Nephrology (Carlton) 2007;12:90-94.

29. Lim JH, Cho JH, Lee JH, et al. Risk factors for recurrent urinary tract infection in kidney transplant recipients. Transplant Proc 2013;45:1584-1589.

30. Mangin M, Sinha R, Fincher K. Inflammation and vitamin D: the infection connection. Inflamm Res 2014;63:803-819.

31. Adams JS, Hewison M. Unexpected actions of vitamin D: new perspectives on the regulation of innate and adaptive immunity. Nat Clin Pract Endocrinol Metab 2008;4:8090.

32. Bienaime F, Girard D, Anglicheau D, et al. Vitamin D status and outcomes after renal transplantation. J Am Soc 
Nephrol 2013;24:831-841.

33. Sezer S, Yavuz D, Canoz MB, Ozdemir FN, Haberal M. Vitamin D status, bone mineral density, and inflammation in kidney transplantation patients. Transplant Proc 2009;41:2823-2825.

34. Courbebaisse M, Xu-Dubois YC, Thervet E, et al. Cholecalciferol supplementation does not protect against renal allograft structural and functional deterioration: a retrospective study. Transplantation 2011;91:207-212.

35. Ozdemir BH, Ozdemir AA, Sezer S, Colak T, Haberal M. Influence of 1,25-dihydroxyvitamin $\mathrm{D}_{3}$ on human leukocyte antigen-DR expression, macrophage infiltration, and graft survival in renal allografts. Transplant Proc 2011;43:500-503.

36. Tanaci N, Karakose H, Guvener N, Tutuncu NB, Colak T, Haberal M. Influence of 1,25-dihydroxyvitamin $\mathrm{D}_{3}$ as an immunomodulator in renal transplant recipients: a retrospective cohort study. Transplant Proc 2003;35:28852887.

37. Uyar M, Sezer S, Arat Z, Elsurer R, Ozdemir FN, Haberal M. 1,25-Dihydroxyvitamin $\mathrm{D}(3)$ therapy is protective for renal function and prevents hyperparathyroidism in renal allograft recipients. Transplant Proc 2006;38:2069-2073. 